\title{
Radionuclides from Chernobyl hot particles in the environment of North-Eastern Poland - A leaching experiment
}

\author{
J.W. Mietelski
}

The Henry Niewodniczanski Institute of Nuclear Physics, 31-342 Krakow, Poland

\begin{abstract}
The north-eastern Poland is the area whese fallout of Chernobyl "fuel-like hot-particles" occurred. Experiment on the leaching out of radionuclides from forest litter was performed. Five samples were subscquently leached out by: a weak hydrochloric acid (fulvic acid fraction), ammonia water (hurnic acid fraction) and $2 \mathrm{M} \mathrm{HCl}$ (soluble fraction). Residue was analysed as well, after full mineralisation. Results on total activities and its distribution between fractions obtained for. ${ }^{137} \mathrm{Cs},{ }^{\infty} \mathrm{Sr}$, ${ }^{239+240} \mathrm{Pu},{ }^{238} \mathrm{Pu}$ and ${ }^{241} \mathrm{Am}$ are presented. Relatively high activities of plutonium were observed in humic acid fractions. This founding support suggestions by other authors on possible complexing of Pu by humic acid.
\end{abstract}

\section{INTRODUCTION}

A fallout of small „fuel-like hot particles" (HP) from initial Chemobyl plume was found in the farthest north-eastern Poland [1-3]. The fallout density, calculated from observed plutonium activity, gave approximately $2500 \mathrm{HPs}$ per square meter [4], if the particle size was assumed to be equal to $4.4 \mu \mathrm{m}$ $[5,6]$. Those particles should be rather classified as "explosion origin" [7] particles. As treated by high temperature the radionuclides within the HP were initially most likely in an insoluble forms. Then, after many years of a decomposition (corrosion) in environmental conditions radionuclides from HPs might be leached out and might go to different chemical forms. Pu, Am or $\mathrm{Cm}$ could be bio-available or more general speaking leachable mostly if they are complexed by humic or fulvic acids [8-11]. To prove this feature present experiment was performed. Fulvic acid [12] is a mixture of colloids from soil solution, which are soluble at both acid and basic conditions and it could be filtrated through $0.45 \mu \mathrm{m}$ pore diameter filters Humic acid [12] is also a mixure of soil solution colloids. Although it is soluble at basic conditions, it precipitates in weak acids. It also could be filtrated through $0.45 \mu \mathrm{m}$ pore diameter filters.

\section{MATERIAL AND METHOD}

During the Summer of 1999 in seven locations of Primeval Forest of Augustow (North-Eastern Poland, approximately $23^{\circ} 20^{\prime} \mathrm{E}, 53^{\circ} 50^{\prime} \mathrm{N}$ ) about 20 samples of forest litter or soil were collected. Initially all the samples were measured using a low-background gamma spectrometer (results were not published yet). Besides the dominating activity of ${ }^{137} \mathrm{Cs}$, some traces of ${ }^{241} \mathrm{Am}$ and ${ }^{154} \mathrm{Eu}$ were observed there as well. The observation of the latest nuclide confirms the presence of HPs in samples, since it is well known indicator for Chemobyl fuel-like HPs $[13,3]$.

An experiment on the leaching of the nuclides from the samples, among them: ${ }^{137} \mathrm{Cs},{ }^{90} \mathrm{Sr},{ }^{241} \mathrm{Am}$, and ${ }^{238,239+240} \mathrm{Pu}$ was performed. Five samples originating from two locations were taken for it. Samples were subsequent layers of forest litter about $2 \mathrm{~cm}$ thick, collected in old spruce forest (sample 1, two layers) or in young pine wood (sample 2, three layers). Nuclides of interest were also ${ }^{154}$ Eu (and other rare earths isotopes, for example ${ }^{147} \mathrm{Sm}$ ) and uranium as well as thorium isotopes, for comparison. 
However, the measurements for the latest nuclides were not finished before the start of the Conference. This will be completed later.

Main steps of the experiment consist a sequential treatment as follow:

1. leaching out by diluted $\mathrm{HCl}(\mathrm{pH}-3.5)$ and next filtration with $0.7 \mu \mathrm{m}$ pore diameter membrane filter (fulvic acid fraction),

2. leaching out by diluted $\mathrm{NH}_{4}(\mathrm{pH} \sim 9$ ) and next filtration with $0.7 \mu \mathrm{m}$ pore diameter membrane filter (bumic acid fraction),

3. leaching out by $2 \mathrm{M} \mathrm{HCl}$ solution (soluble fraction),

4. final full decomposition (ashing, $\mathrm{HF}, \mathrm{HNO}_{3}, \mathrm{HCl}, \mathrm{H}_{3} \mathrm{BO}_{3}$ ) of remaining sample matrix (refractory fraction).

All the leaching were performed by immersing the powdered and air dried samples within a plastic $1 \mathrm{~L}$ bottle containing $700 \mathrm{ml}$ of a given solution. The bottle was shaken for about 10 minutes. For fulvic and humic acids fractions the pH was then adjusted to proper value (3.5 or 9 , respectively). The solution was left overnight, always several time shaken during this period. The solution was roughly filtered using a glass fibre filter (Whatman EPM 1000). The filter itself, after drying, was then combined with sample for next steps. Then, in cases of two first fractions (fulvic and humic acids) of all five samples the solutions were purified by a second filtration, using vacuum pump and membrane filters of $0.7 \mu \mathrm{m}$ pore diameters to remove any possible tiny particles. We used $0.7 \mu \mathrm{m}$ filters instead of $0.45 \mu \mathrm{m}$ ones, which should be used accordingly to exact definitions [12]. It was done only due to some practical problems with equipment - we have such filters with practically unlimited area what helped a lot with effective filtration.. Each liquid fraction was then evaporated (some nitric acid was added during this to do an initial mineralization). Dry material was then measured on low-background gamma spectrometer with HPGe detector (Silena Ltd).

For first three liquid fractions the procedure consist of the treatment with hot $\mathrm{HClO}_{4}, \mathrm{H}_{2} \mathrm{O}_{2}$ and $\mathrm{HNO}_{3}$. The refractory fraction samples were ashed in $450^{\circ} \mathrm{C}$. For a sub-sample of about $10 \mathrm{~g}$ of ash of each one original sample a typical mineralisation procedure [14] was applied next. Tracers $\left({ }^{236} \mathrm{Pu},{ }^{232} \mathrm{U}\right.$, ${ }^{243} \mathrm{Am},{ }^{148} \mathrm{Gd}$ ) were added in all cases prior to the wet mineralisation. Added activities were below 10 $\mathrm{mBq}$ per sample for each tracer, except for $\mathrm{Gd}$ isotope for which it was $21.7 \mathrm{mBq} / \mathrm{sample}$. Radiological purity of each tracer was tested. A combined radiochemical procedure was applied for the subsequent determination of all examined nuclides. The separation order was: $\mathrm{Cs}$ before any radiochemistry, Th and $\mathrm{Pu}, \mathrm{Sr}, \mathrm{U}$, rare earths and $\mathrm{Am}-\mathrm{Cm}$. Plutonium and thorium were separated after the adjustment of the $\mathrm{Pu}$ oxidation step [14] using DOWEX-1 anion exchange pressurised columns [4] when the samples were dissolved in $8 \mathrm{M} \mathrm{HNO}_{3}$. Strontium was separated just from $8 \mathrm{M} \mathrm{HNO}_{3}$ effluent using Sr-resin produced by Eichrom Ltd., and the polyethylene columns long for $9 \mathrm{~cm}$ and having $7 \mathrm{~mm}$ of inner diameter. The recovery was only assumed on the basis of the tests using blanks spiked with ${ }^{90} \mathrm{Sr}$ (the average recovery was then assumed equal to $80 \pm 10 \%$ ). Uranium was separated in effluent of $\mathrm{Sr}$-resin column after coprecipitation of hydroxides at $\mathrm{pH}=9$. The precipitate was centrifuged, dissolved in concentrate $\mathrm{HCl}$, converted to $9 \mathrm{M} \mathrm{HCl}$ and passed through the free-flow DOWEX-1 anion exchange column, $12 \mathrm{~cm}$ high with $7 \mathrm{~mm}$ inner diameter. Uranium was then stripped off using $8 \mathrm{M} \mathrm{HNO}_{3}$ and then water [15]. From the effluent the rare-earths and $\mathrm{Am}-\mathrm{Cm}$ isotopes were separated using a typical procedure [16] only very slightly modified, as it was described in a previous article [17]. All alpha spectrometric sources were prepared using $\mathrm{NdF}_{3}$ method [18,14], and measured on Silena AlphaQuattro spectrometer with Canberra PIPS detectors. The ${ }^{90} \mathrm{Sr}$ was measured using liquid scintillation spectrometer Wallac Gurdian 1414-003 with Hi-Safe 3 cocktail and plastic, diffuse type vessels. The total activity of samples was calculated by summing up the activities of given nuclide in all four fractions.

\section{RESULTS AND CONCLUSIONS}

At present stage the results for ${ }^{137} \mathrm{Cs},{ }^{90} \mathrm{Sr},{ }^{238,239+240} \mathrm{Pu}$, and initial for ${ }^{241} \mathrm{Am}$ are available. The results on total activity of all those radionuclides (and for ${ }^{134} \mathrm{Cs}$ ) are presented in Table 1. Observed activities do not differ much from the typical values found on this area before $[3,4,16,19]$. This confirms the previous 
suggestions on quasi-homogenious deposition of small hot particles [3] fallout on this area. Results on leaching experiment for ${ }^{137} \mathrm{Cs},{ }^{239+240} \mathrm{Pu},{ }^{238} \mathrm{Pu},{ }^{90} \mathrm{Sr},{ }^{241} \mathrm{Am}$ are presented in Figs. 1-5, respectively.

Table 1 : Results on the total activity determined for samples at site 1 (two layers) and site 2 (tree layers), activities are corrected for decay for sampling date (1.08.1999). Uncertainties are lo, counting only.

\begin{tabular}{cccccc}
\hline Activity & $1-1$ & $1-2$ & $2-1$ & $2-2$ & $2-3$ \\
{$[\mathrm{~Bq} / \mathrm{kg}]$} & $(0-2 \mathrm{~cm})$ & $(2-4 \mathrm{~cm})$ & $(0-2 \mathrm{~cm})$ & $(2-4 \mathrm{~cm})$ & $(4-6 \mathrm{~cm})$ \\
\hline${ }^{137} \mathrm{Cs}$ & $172 \pm 4$ & $123 \pm 6$ & $229 \pm 6$ & $316 \pm 6$ & $197 \pm 9$ \\
${ }^{134} \mathrm{Cs}$ & $0.8 \pm 0.4$ & $1.0 \pm 0.2$ & $0.7 \pm 0.3$ & $2.1 \pm 0.2$ & $1.4 \pm 0.2$ \\
${ }^{239+240} \mathrm{Pu}$ & $0.30 \pm 0.02$ & $0.83 \pm 0.06$ & $0.31 \pm 0.02$ & $1.22 \pm 0.06$ & $1.03 \pm 0.06$ \\
${ }^{238} \mathrm{Pu}$ & $0.11 \pm 0.01$ & $0.21 \pm 0.01$ & $0.12 \pm 0.1$ & $0.42 \pm 0.02$ & $0.31 \pm 0.02$ \\
${ }^{90} \mathrm{Sr}$ & $24.7 \pm 0.5$ & $9.9 \pm 0.4$ & $10.5 \pm 0.4$ & $32.3 \pm 0.4$ & $15.2 \pm 0.4$ \\
${ }^{241} \mathrm{Am}$ & $0.87 \pm 0.20$ & $0.46 \pm 0.04$ & $1.04 \pm 0.09$ & $1.09 \pm 0.07$ & $0.76 \pm 0.29$ \\
\hline
\end{tabular}

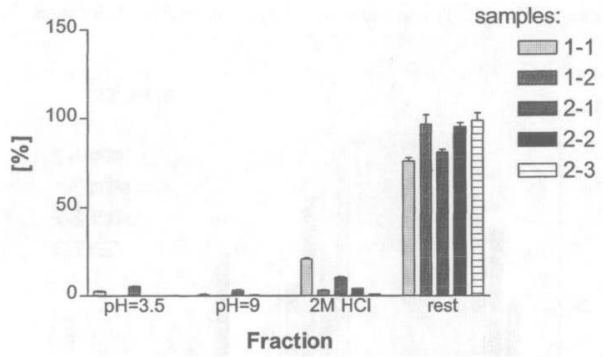

Figure 1 : Percentage of the total activity of ${ }^{137} \mathrm{Cs}$ observed in given sample and for given chemical fraction

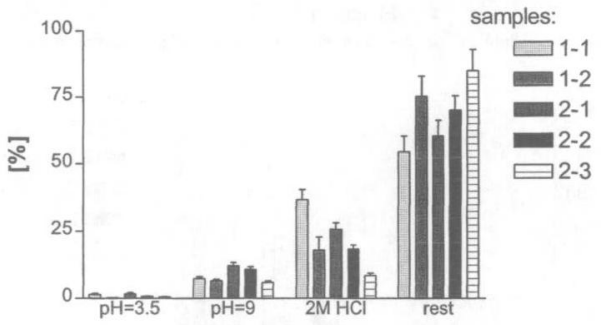

Fraction

Figure 2 : Percentage of the total activity of ${ }^{239+240} \mathrm{Pu}$ observed in given sample and for given chemical fraction. 


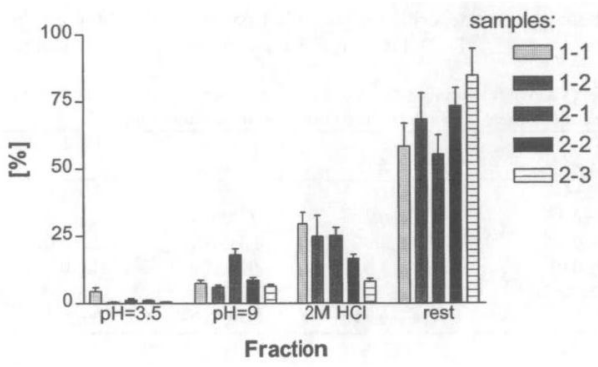

Figure3 ; Percentage of the total activity of ${ }^{233} \mathrm{Pu}$ observed in given sample and for given chemical fraction.

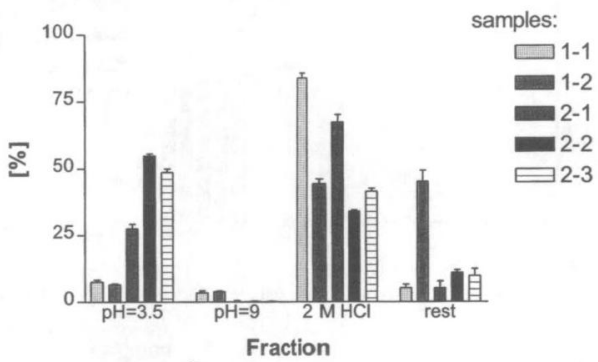

Figure 4 : Percentage of the total activity of ${ }^{90} \mathrm{Sr}$ observed in given sample and for given chemical fraction.

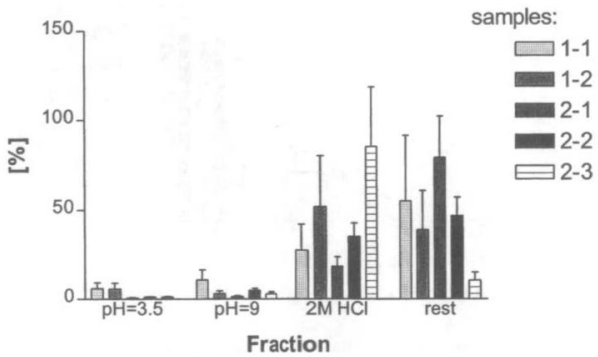

Figure 5 : Percentage of the total activity of ${ }^{241}$ Am observed in given sample and for given chemical fraction. 
An important differences between the radionuclides behaviour might be noticed. Almost all redioceasium was not leached off the samples with any used liquids, whereas for example ${ }^{90} \mathrm{Sr}$ seems to be relatively easy leachible in weak or stronger acid conditions. Cs and $\mathrm{Pu}$ from upper layers seems to be more a little bit more easy leachable in $2 \mathrm{M} \mathrm{HCl}$ while compare it to that from deeper layers. However, the most interesting feature is relatively high activity of plutonium isotopes in humic acid fractions, i.e. in basic conditions, at $\mathrm{pH}$ such high as equal to 9 . Although a little to large pore diameter filters were used, which might allow some of tin particles to go through it, the lack of other nuclides (especially $\mathrm{Sr}, \mathrm{Cs}$ ) excludes this explanation. It rather suggests complexing by humic acid as the only reason of plutonium presence. This results strongly supports some earlier results by other authors [8-11] on the possibility of a humic acid complexation of plutonium, (but not the fulvic acid complexation) which then might be sometimes (in basic conditions) far more mobile in the environment then it was classically assumed.

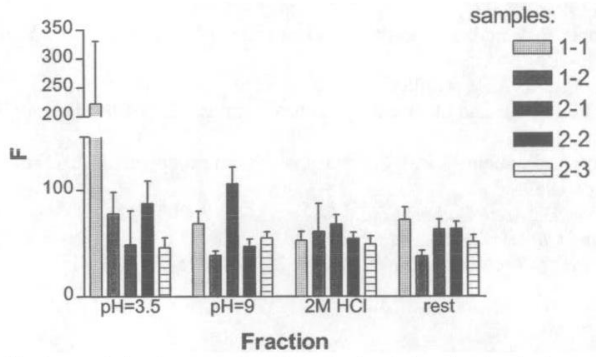

Flgure 6: Chernobyl fraction $F$ of plutonium (calculated from the simple formula given in the previous article [4]) observed in different chemical fraction of samples.

In Fig. 6 the Chernobyl fraction of plutonium calculated on the basis of ${ }^{238} \mathrm{Pu}$ to ${ }^{239+240} \mathrm{Pu}$ activity ration analyses [4] is presented. As one could expect, Chernobyl plutonium is relatively a little more abundant in surface layers than in deeper ones. However, from figures 2 and 3 it seems that Pu from upper layers seems to be more easy leachable than from deeper ones. This might suggests, that Chernobyl plutonium is a little more easier leachable than the global fallout one.

\section{Acknowledgements}

The author is grateful to Polish Science Committee for Scientific Researches for the financial support of the investigations and his participation to the Conference within a grant No 6P04G07520.

\section{References}

[1] Pieńkowski L., Jastrzębski J., Tys T., Batsch T., Jaracz P., Kurcewicz W., Mirowski S., Szeflińska G., Szefliński Z., Szweryn B., Wilhelmi Z. and Józefowicz E.T., J. of Radioanal and Nucl. Chem., L. 117 (1987) 6; 379-411.

[2] Broda R.: Acta Physica Polonica 18 (1987) No 10, 935-950.

[3] Mietelski J.W., Nukleonika, 43 No 4 (1998), 449-458.

[4] Mietelski J.W. and Was B., Appl. Rad. and Isot., 46 (1995), 1203-1211.

[5] Rudhard J., Schell B., Lindner G.: Size Distribution of Hot Particles in the Chernobyl Fallout; International Symposium on Radioecology: Chemical Speciation - Hot Particle", Znojmo, Czech Republic, 12-16 Oct. 1992,

[6] Cuddlhy R. G., Finch G.L., .Newton G.J., Hahn F.F., Mewhinney J.A., Rothenberg S.J. and Powers D.A., Environ. Sci. Technology 23 (1989) 89-95. 
[7] Salbu B., Actinides associated with particles, Plutonium in the Environment, Ed. A.Kudo, p. 121-138, Elsevier, Amsterdam, ..., Tokyo, 2001.

[8] Mahara Y., Kudo A., Appl. Rad. and Isot., 46(1995), p. 1191-1202

[9] Y.Zhang, X.Zhao, L.Wei, Z.Lin, D.Wang, Complex formation of americium III with humic acid: Book of Extended Abstract of 4th International Conference on Nuclear and Radiochemistry, St. Malo 8-13. IX 1996, Vol. II, p. EP-63, Eds J.David and J.C.Krupa.

[10] Alberts J.J., Wahlgren M.A., Orlandini K.A., Durbahn C.A., J.Environ. Radioact. 9 (1989) 89-96.

[11] Fujikawa Y., Zheng J., Cayer I., Sugahara M., Takigami H., Kudo A., J.Radioanal. and Nucl. Chem. 240 (1999) 69-74.

[12] Filella M., Parthasarathy N., Buffle J., Humic and Fulvic Componds, Encyclopedia of Analytical Science, Eds. A.Townshend, Vol. 4, p.2017-2027, Academic Press, London,...,Toronto, 1995.

[13] Jaracz P., Mirowski S., Trzcińska A., Isajenko K., Jagielak J., Kempisty T. and Józefowicz E.T., J. Environ. Rad. 26 (1995), 83-97.

[14] LaRosa J.J., Cooper E., Ghods A., Jansta V., Makarewicz M., Shawky S. and Vajda N., J. Environ. Rad. 17 (1992), 183-209.

[15] Mietelski J.W., Bacza A.S., Guillen J., Buzinny M., Tsigankov N., Gaca P., Jasińska M., Tomankiewicz E. Plutonium and other alpha emitters in mushrooms from Poland, Spain and Ukraine (in preparation)

[16] Measurements of Radionuclides in the Food and the Environment, IAEA Technical Report 295, IAEA Press, Vienna 1989.

[17] Mietelski J.W., Was B., Appl. Rad. and Isot., 48 No. 5 (1997) 705-713.

[18] Sill C.W. Nucl, and Chem. Waste Mgmt., 7 (1987), 201-215.

[19] Mietelski J.W., Postepy Techniki Jqdrowej 37 No. 3 (1994), 15-33 (in Polish) 